\title{
Evaluation of population impact of candidate polymorphisms for coronary heart disease in the Framingham Heart Study Offspring Cohort
}

\author{
Yu Yan ${ }^{1}$, Yijuan $\mathrm{Hu}^{2}$, Kari E North*1,3, Nora Franceschini ${ }^{1}$ and Danyu Lin $^{2}$
}

Addresses: ${ }^{1}$ Department of Epidemiology, University of North Carolina, 2101 McGavran-Greenberg Hall, Chapel Hill, North Carolina 27599, USA, ${ }^{2}$ Department of Biostatistics, University of North Carolina, 3101 McGavran-Greenberg Hall, Chapel Hill, North Carolina 27599, USA and ${ }^{3}$ Carolina Center for Genome Sciences, University of North Carolina, 5009 Genetic Medicine Building, Chapel Hill, North Carolina 27599, USA

E-mail: Yu Yan - yuyan.unc@gmail.com; Yijuan Hu - yhu@bios.unc.edu; Kari E North* - kari_north@unc.edu;

Nora Franceschini - noraf@unc.edu; Danyu Lin - lin@bios.unc.edu

*Corresponding author

from Genetic Analysis Workshop 16

St Louis, MO, USA 17-20 September 2009

Published: 15 December 2009

BMC Proceedings 2009, 3(Suppl 7):SII8 doi: 10.1I86/I753-656I-3-S7-SII 8

This article is available from: http://www.biomedcentral.com/I753-656I/3/S7/SII8

(c) 2009 Yan et al; licensee BioMed Central Ltd.

This is an open access article distributed under the terms of the Creative Commons Attribution License (http://creativecommons.org/licenses/by/2.0), which permits unrestricted use, distribution, and reproduction in any medium, provided the original work is properly cited.

\begin{abstract}
In order to evaluate the population impact of putative causal genetic variants over the life course of disease, we extended the static estimation of population-attributable risk fraction and developed a novel tool to evaluate how the population impact changes over time using the Framingham Heart Study Offspring Cohort data provided to the Genetic Analysis Workshop 16, Problem 2. A set of population-attributable risk fractions based on survival functions were estimated under the proportional hazards models. The development of this novel measure of population impact creates a more comprehensive estimate of population impact over the life course of disease, which may help us to better understand genetic susceptibility at the population level.
\end{abstract}

\section{Background}

The ongoing discovery of new genetic markers from genome-wide association studies presents opportunities and challenges for scientists to evaluate these new biomarkers. One of the critical questions that has been raised is how to evaluate the potential population impact of these new markers. First proposed by Levin in 1953 [1], the primary measure of impact is the population-attributable risk fraction (PAF, also known as the population-attributable risk proportion). The PAF, determined by the prevalence of exposure and the magnitude of association, measures the proportion of disease risk in the total population associated with one or multiple exposures; thus the PAF is useful in evaluating the impact of different exposures at the population level. However, the current PAF estimation does not account for age of onset data (i.e., time-to-event data). In this study, we developed methodological approaches to estimate the population impact of genetic variants over the life course of disease using the longitudinal Framingham Heart Study Offspring Cohort and incident coronary heart disease (CHD) events. 


\section{Methods}

\section{Population and phenotype}

We used the Framingham Heart Study Offspring Cohort data provided to the Genetic Analysis Workshop (GAW) 16, Problem 2, for the analyses. The Framingham Heart Study is a longitudinal community-based cohort of cardiovascular disease and its risk factors that began in 1948 with the recruitment of the Original Cohort [2]. Between 1971 and 1975, 5124 children or spouses of the Original Cohort were enrolled into the Offspring Cohort [3]. The Offspring Cohort has undergone eight examinations every 4 to 8 years. The present study is composed of unrelated Offspring participants. Of 2760 Offspring participants who gave informed consent for data collected to be used by anyone, we excluded those biologically related participants $(n=813)$, participants without genotyping data $(n=211)$, and those with prevalent CHD at baseline $(n=2)$. After these exclusions, a total of 1734 unrelated Offspring participants were available for analysis. The Framingham Heart Study Offspring Cohort study protocol was approved by Boston University Medical Center Institutional Review Board and this investigation was approved by University of North Carolina at Chapel Hill Institutional Review Board.

A CHD event was defined as any of the following: recognized myocardial infarction diagnosed through an electrocardiogram or enzymes, coronary insufficiency, or death attributed to CHD.

\section{Genotyping methods and single-nucleotide polymorphism (SNP) selection}

The Affymetric $500 \mathrm{k}$ chip was used to genotype individual participant DNA. SNPs selected for this study were based on published candidate gene studies and genome-wide association studies. A total of 23 SNPs associated with major CHD or major cardiovascular disease were included in this investigation.

\section{Statistical analyses}

To assess whether genotype distributions departed from Hardy-Weinberg equilibrium, a $\chi^{2}$ goodness-of-fit test was used. We used Cox proportional hazards to estimate the hazard ratios and 95\% confidence intervals of incident CHD. The hazard function was formulated on the age scale using the age at onset of CHD obtained as part of the GAW 16 Problem 2 data release. Covariates, including sex, smoking, diabetes, systolic blood pressure, anti-hypertensive treatment, total cholesterol levels, high-density lipoprotein cholesterol, and body mass index, were included in the models to reduce the residual variance. The association was considered to be significant if the $p$-value was less than 0.05. Assuming additive inheritance, a variable taking on the values 0 for reference genotype, 1 for heterozygous genotype, and 2 for homozygous genotype was used to test genetic effects for each SNP.

Significant associations between three SNPs (rs1333049, rs618675, and rs1376251) and increased risk of incident CHD were noted. We further explored the association with the risk score, which was constructed by summing the number of risk alleles across these three CHD susceptibility SNPs. The distribution ranged from zero to six alleles. Because very few participants have zero $(n=27)$ or six $(n=8)$ risk alleles, these participants were included into the closest group (e.g., zero was grouped with one risk allele).

Our methodological approach integrates multiple PAF estimates at multiple ages for a single variant in an attempt to create a comprehensive estimate of population impact.

For a binary disease status $D$ and a binary exposure indicator $E$, the PAF is defined as

$$
A=\frac{\operatorname{Pr}(D=1)-\operatorname{Pr}(D=1 \mid E=0)}{\operatorname{Pr}(D=1)}
$$

[1]. We extended this static measure to the age-of-onset data with potentially multiple risk factors

$$
A(t)=\frac{\operatorname{Pr}(T \leq t)-\operatorname{Pr}(T \leq t \mid X=0)}{\operatorname{Pr}(T \leq t)}
$$

where $T$ denotes the time to disease and $X$ denotes a set of potential genetic factors. We can rewrite this measure in terms of survival function

$$
A(t)=\frac{S_{0}(t)-S(t)}{1-S(t)}
$$

and $S(t)=\operatorname{Pr}(T>t)$ and $S_{0}(t)=\operatorname{Pr}(T>t \mid X=0)$.

$S(t)$ was estimated by the Kaplan-Meier nonparametric method. If $X$ pertained to a single genetic variant, then we estimated $S_{0}(t)$ by the Kaplan-Meier method as well. If $X$ consisted of several genetic factors, then we estimated $S_{0}(t)$ under a semiparametric regression model. All the statistical analyses were performed in SAS 9.1 (SAS institute, Cary, NC). A PAF plot was provided to indicate how the population impact changed over the life course of disease.

\section{Results}

A total of 137 incident CHD events were identified. The allele frequencies for all 23 SNPs analyzed in this study were in Hardy-Weinberg equilibrium $(p>0.01)$. Because 
the estimates for SNP effects on incident CHD were almost identical after adjusting for aforementioned covariates, only unadjusted hazard ratios with 95\% confidence intervals were reported (Table 1). Three SNPs (rs1333049 close to the CDKN2A/2B gene, rs618675 in the GJA4 gene, and rs1376251 in the TAS2R50 gene) were significantly associated with the incident CHD (Table 1). Further exploration indicated that the risk score $(p=0.0004)$ was significantly associated with incident CHD risk (Table 1).

The PAF plots for the risk score and three significant SNPs with and without adjustment for covariates are shown in Figure 1. The age at onset of CHD ranged from 41 to 81 years old. The PAFs were much higher for the risk score (PAF $=41 \%$ on average) than for each individual SNP. The unadjusted PAFs showed a subtle decline with age, whereas the adjusted PAFs slightly increased over time.

\section{Discussion}

Our study replicates the association between CHD risk and rs1333049 close to the CDKN2A/2B gene, rs618675 in the GJA4 gene, and rs1376251 in the TAS2R50 gene, in Caucasians. However, the number of events (maximum of 137 for CHD) was small. Thus, we had limited power to detect association for each individual SNP and our study results need to be validated in different, large population-based studies.

We assessed here the impact of the known cardiovascular disease genes/loci on the population burden of CHD over time, based on data from the Framingham Heart Study Offspring Cohort. Static PAFs have been

Table I: Characteristics of selected SNPs, and associations between the CHD incidence and SNPs

\begin{tabular}{|c|c|c|c|c|c|c|c|c|c|}
\hline \multirow[b]{2}{*}{$\begin{array}{l}\text { Closest } \\
\text { gene }\end{array}$} & \multirow[b]{2}{*}{ Gene name } & \multirow[b]{2}{*}{$\begin{array}{l}\text { SNP } \\
\text { [reference] }\end{array}$} & \multirow[b]{2}{*}{ Chr } & \multirow[b]{2}{*}{$\begin{array}{l}\text { Physical } \\
\text { position }\end{array}$} & \multirow[b]{2}{*}{ Risk allele } & \multirow[b]{2}{*}{ MAF } & \multicolumn{3}{|c|}{ HR estimates $(95 \% \mathrm{Cl})$} \\
\hline & & & & & & & $\begin{array}{l}\text { Heterozygous } \\
\text { genotype }\end{array}$ & $\begin{array}{l}\text { Homozygous } \\
\text { genotype }\end{array}$ & $p$-Value \\
\hline GJA4 & gap junction protein, alpha 4 & rs6I8675 [4] & I & 34922761 & C & 0.19 & $1.32(1.01,1.72)$ & I.73 (1.01, 2.97) & 0.0451 \\
\hline PCSK9 & $\begin{array}{l}\text { proprotein convertase } \\
\text { subtilisin/kexin type } 9\end{array}$ & rs2 II4580 [4] & I & 55167236 & $A$ & 0.24 & $1.22(0.94,1.59)$ & $1.49(0.88,2.54)$ & 0.1376 \\
\hline PSRCI & $\begin{array}{l}\text { proline/serine-rich } \\
\text { coiled-coil I }\end{array}$ & rs599839 [5] & 1 & 109623689 & $A$ & 0.22 & $1.05(0.79,1.41)$ & I.II (0.62, I.98) & 0.7262 \\
\hline MIA3 & $\begin{array}{l}\text { melanoma inhibitory activity } \\
\text { family, member } 3\end{array}$ & rsI7465637 [5] & I & 220890152 & $\mathrm{C}$ & 0.29 & $1.07(0.82,1.39)$ & I.I $4(0.67,1.93)$ & 0.6282 \\
\hline FMN2 & formin 2 & rsl7672I35[6] & I & 238512219 & C & 0.11 & $1.20(0.83,1.73)$ & $1.44(0.69,2.99)$ & 0.3286 \\
\hline \multirow[t]{3}{*}{$O R / 3 G I$} & $\begin{array}{l}\text { olfactory receptor, family I3, } \\
\text { subfamily G, member I }\end{array}$ & rsII5I640[7] & 1 & 245902573 & C & 0.43 & $0.98(0.77,1.25)$ & $0.96(0.59,1.56)$ & 0.8628 \\
\hline & & rs2943634 [5] & 2 & 226776324 & C & 0.35 & $1.08(0.84,1.39)$ & $1.16(0.71,1.92)$ & 0.5508 \\
\hline & & rs $105 \mid 6882$ [4] & 4 & 92127599 & C & 0.17 & $1.19(0.85,1.67)$ & $|.4|(0.72,2.78)$ & 0.3170 \\
\hline THBS4 & thrombospondin 4 & rs264986 [4] & 5 & 79206180 & $\mathrm{~T}$ & 0.27 & $1.01(0.77,1.32)$ & $1.01(0.59,1.74)$ & 0.9656 \\
\hline MTHFDIL & $\begin{array}{l}\text { methylenetetrahydrofolate } \\
\text { dehydrogenase I-like }\end{array}$ & rs6922269 [5] & 6 & $15 \mid 294678$ & A & 0.27 & $1.13(0.87,1.48)$ & $1.29(0.76,2.18)$ & 0.3506 \\
\hline PHACTRI & $\begin{array}{l}\text { phosphatase and actin } \\
\text { regulator I }\end{array}$ & rsI5I24II [4] & 6 & 13439076 & C & 0.34 & $\mathrm{I} .0 \mathrm{I}(0.78, \mathrm{I} .3 \mathrm{I})$ & $\mathrm{I} .03(0.6 \mathrm{I}, \mathrm{I} .7 \mathrm{I})$ & 0.9235 \\
\hline WNT2 & $\begin{array}{l}\text { wingless-type MMTV } \\
\text { integration site family } \\
\text { member } 2\end{array}$ & rs39312 [4] & 7 & || $674202 \mid$ & $A$ & 0.35 & $1.06(0.83,1.35)$ & I.I2 (0.68, I.83) & 0.6554 \\
\hline \multirow[t]{2}{*}{$C D K N 2 A / 2 B$} & $\begin{array}{l}\text { cyclin-dependent kinase } \\
\text { inhibitor } 2 A / 2 B\end{array}$ & rsl333049 [6] & 9 & 22115503 & C & 0.48 & $1.28(1.01,1.63)$ & $1.64(1.02,2.66)$ & 0.0433 \\
\hline & & rs50II 20 [5] & 10 & 44073873 & C & 0.14 & $0.99(0.71,1.39)$ & $0.99(0.50,1.94)$ & 0.9681 \\
\hline KIAA0528 & KIAA0528 & rsI0505879 [4] & 12 & 22539123 & G & 0.22 & $1.13(0.86,1.50)$ & $1.28(0.74,2.24)$ & 0.3753 \\
\hline TAS2R50 & $\begin{array}{l}\text { taste receptor, type } 2 \text {, } \\
\text { member } 50\end{array}$ & rs|37625I [7] & 12 & 11030119 & C & 0.33 & $1.31(1.00,1.71)$ & 1.71 (1.01, 2.92) & 0.0476 \\
\hline \multirow[t]{3}{*}{ ALOX5AP } & $\begin{array}{l}\text { arachidonate } 5 \text {-lipoxygenase- } \\
\text { activating protein }\end{array}$ & rs7984952 [4] & 13 & 30129806 & $\mathrm{~T}$ & 0.43 & $1.24(0.97,1.58)$ & $\mathrm{I} .54(0.95,2.5 \mathrm{I})$ & 0.0817 \\
\hline & & rs7995384 [4] & 13 & 30177259 & $\mathrm{~T}$ & 0.29 & $1.20(0.92,1.57)$ & $1.44(0.84,2.48)$ & 0.1830 \\
\hline & & rsII7395 [4] & 13 & 30365911 & $\mathrm{~T}$ & 0.13 & $1.09(0.75,1.59)$ & $1.19(0.56,2.52)$ & 0.6459 \\
\hline \multirow[t]{2}{*}{ SMAD3 } & SMAD family member 3 & rs $172282 \mid 2[5]$ & 15 & 65245693 & C & 0.29 & $1.04(0.80,1.35)$ & $1.08(0.64,1.81)$ & 0.7781 \\
\hline & & rs25495I3 [4] & 16 & 78108228 & C & 0.13 & $1.03(0.73,1.47)$ & $1.06(0.53,2.15)$ & 0.8617 \\
\hline $\mathrm{CDH} / 3$ & cadherin $\mathrm{I} 3, \mathrm{H}$-cadherin & rs8055236 [6] & 16 & 81769899 & $\mathrm{~T}$ & 0.19 & $1.26(0.95,1.67)$ & $1.59(0.91,2.78)$ & 0.1045 \\
\hline SEZ6L & seizure related 6 homolog & rs688034 [6] & 22 & 25019635 & C & 0.33 & $1.10(0.84,1.43)$ & $1.20(0.71,2.04)$ & 0.4971 \\
\hline Risk Score ${ }^{a}$ & & & & & & & $1.32(1.13,1.54)$ & & 0.0004 \\
\hline
\end{tabular}

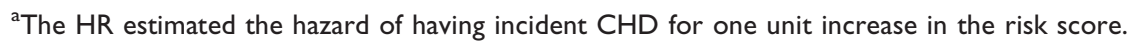


Panel A. Unadjusted PAF plot.

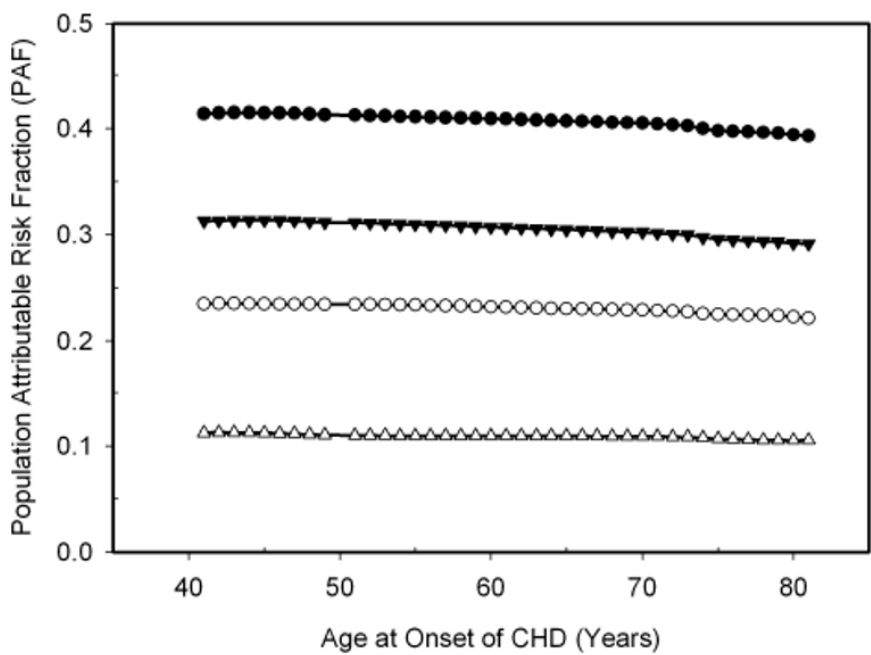

Panel B. Adjusted PAF plot.

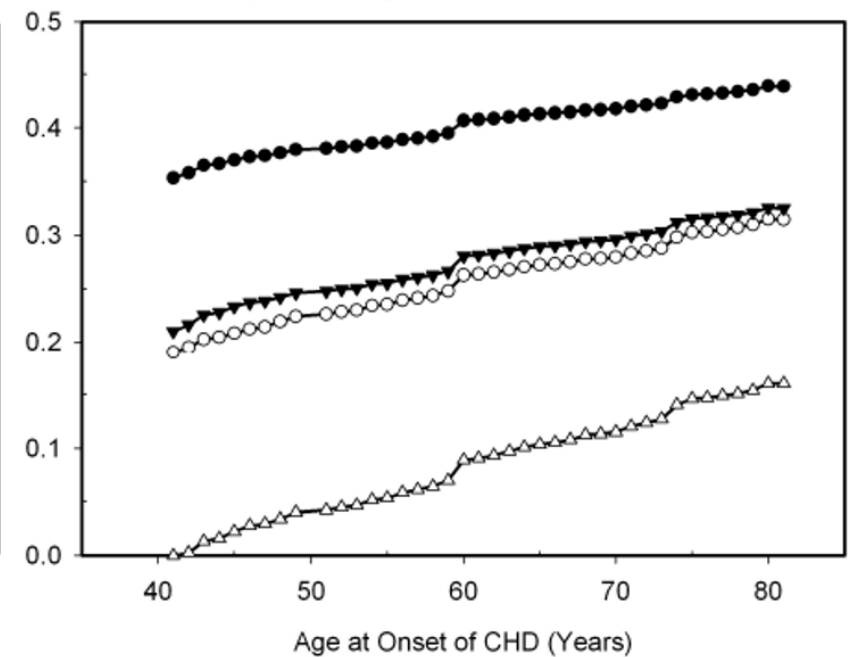

Figure I

The PAF plot over time for the risk score, rsI333049, rs I37625I, and rs6I8675.

extensively used to rank risk factors and to assess the prospective gains in disease prevention. In this study, we extended the static estimation of PAFs and evaluated how the population impact of genetic variants changed over the life course of CHD, as shown in the PAF plot (Figure 1). The unadjusted PAFs associated with genetic variants slightly decreased as age advanced, whereas adjusted PAFs showed a subtle increase with age, which may be due to the small number of events in these data, especially in the early and late age groups. For example, only six CHD events occurred before the age of 45 , whereas eight events occurred after 75. However, we observed much higher PAFs for the risk score compared with each individual SNP, suggesting the importance of evaluating multiple genetic variants for the population impact analysis.

While the use of the risk score summary metric was useful in this population in which no single SNP achieved a large PAF, these estimates should be interpreted with caution because any time we combine SNP effects based on statistical significance and effect size, we will automatically obtain an improved effect estimate and $p$-value.

\section{Conclusion}

Our development of the novel tool for population impact extends the current PAF analyses and creates a more comprehensive estimate of population impact over the life course of disease, which may improve the understanding of genetic risk factors at the population level.

\section{List of abbreviations used}

CHD: Coronary heart disease; GAW: Genetic Analysis Workshop; HR: Hazard ratio; MAF: Minor allele frequency; PAF: Population-attributable risk fraction; SNP: Single-nucleotide polymorphism.

\section{Competing interests}

The authors declare that they have no competing interests.

\section{Authors' contributions}

YY and KEN conceived of the study, performed the statistical analysis, and drafted the manuscript. YH helped performed the statistical analysis and helped to draft the manuscript. NF participated in the study design and helped to draft the manuscript. DL participated in the study design, helped performed the statistical analysis and helped to draft the manuscript. All authors read and approved the final manuscript.

\section{Acknowledgements}

The Genetic Analysis Workshops are supported by NIH grant ROI GM03I575 from the National Institute of General Medical Sciences. 
This article has been published as part of BMC Proceedings Volume 3 Supplement 7, 2009: Genetic Analysis Workshop 16. The full contents of the supplement are available online at http://www.biomedcentral.com/ $1753-656 \mid / 3$ ? issue $=$ S7.

\section{References}

I. Levin ML: The occurrence of lung cancer in man. Acta Unio Int Contra Cancrum 1953, 9:53I-54I.

2. Dawber TR, Meadors GF and Moore FE Jr: Epidemiological approaches to heart disease: the Framingham Study. Am J Public Health Nations Health I95I, 4I:279-28I.

3. Kannel WB, Feinleib M, McNamara PM, Garrison RJ and Castelli WP: An investigation of coronary heart disease in families. The Framingham offspring study. Am J Epidemiol 1979, I I 0:28 I-290.

4. Larson MG Atwood LD Benjamin EJ Cupples LA D'Agostino RB Sr, Fox CS, Govindaraju DR, Guo CY, Heard Costa NL, Hwang SJ, Murabito JM, Newton-Cheh C, O'Donnell CJ, Seshadri S, Vasan RS, Wang T], Wolf PA and Levy D: Framingham Heart Study $100 \mathrm{~K}$ project: genome-wide associations for cardiovascular disease outcomes. BMC Med Genet 2007, 8(Suppl I):S5.

5. Samani NJ, Erdmann J. Hall AS, Henostenberg C Mangino M, Mayer B, Dixon RJ, Meitinger T, Braund P, Wichmann HE, Barrett JH, König IR, Stevens SE, Szymczak S, Tregouet DA, lles MM, Pahlke F, Pollard H, Lieb W, Cambien F, Fischer M, Ouwehand W, Blankenberg S, Balmforth A), Baessler A, Ball SG, Strom TM, Braenne I, Gieger C, Deloukas P, Tobin MD, Ziegler A, Thompson JR, Schunkert $H$ and WTCCC and the Cardiogenics Consortium: Genomewide association analysis of coronary artery disease. N Engl J Med 2007, 357:443-453.

6. Genome-wide association study of 14,000 cases of seven common diseases and 3,000 shared controls. Nature 2007, 447:66I-678.

7. Shiffman D, Ellis SG, Rowland CM, Malloy MJ, Luke MM, lakoubova OA, Pullinger CR, Cassano J, Aouizerat BE, Fenwick RG, Reitz RE, Catanese II, Leong DU, Zellner C, Sninsky |J, Topol EJ, Devlin |J and Kane JP: Identification of four gene variants associated with myocardial infarction. Am J Hum Genet 2005, 77:596-605.
Publish with Bio Med Central and every scientist can read your work free of charge

"BioMed Central will be the most significant development for disseminating the results of biomedical research in our lifetime. "

Sir Paul Nurse, Cancer Research UK

Your research papers will be:

- available free of charge to the entire biomedical community

- peer reviewed and published immediately upon acceptance

- cited in PubMed and archived on PubMed Central

- yours - you keep the copyright
BioMedcentral 